Case Report

\title{
Amnesia in a Patient with Rheumatoid Arthritis: A Case of Granulomatosis with Polyangiitis
}

\author{
Pablo Weilg $\mathbb{D}^{1},{ }^{1}$ Giancarlo Diaz-Zamora $\mathbb{D D}^{1}{ }^{1}$ and Larry Young $\mathbb{D}^{2}$ \\ ${ }^{1}$ MercyOne North Iowa Medical Center, 1000 4th St SW, Mason City, IA 50401, USA \\ ${ }^{2}$ University of Miami, Division of Rheumatology, 1120 NW 14th St, Miami, FL 33136, USA \\ Correspondence should be addressed to Pablo Weilg; pablo.weilg@gmail.com
}

Received 7 August 2020; Accepted 20 October 2020; Published 29 October 2020

Academic Editor: Constantine Saadeh

Copyright (c) 2020 Pablo Weilg et al. This is an open access article distributed under the Creative Commons Attribution License, which permits unrestricted use, distribution, and reproduction in any medium, provided the original work is properly cited.

A 56-year-old male with a history of seropositive rheumatoid arthritis complained of polyarthritis and forgetfulness. The initial CT scan of the head without contrast was negative for acute pathologies. However, as he continued to decline despite being on oral prednisone, an MRI of the head was ordered and revealed a subtle small region of acute infarction in the left mammillary body. He was diagnosed with granulomatosis with polyangiitis in light of his positive C-ANCA antibodies, PR3 antibody, and a kidney biopsy, which showed focal necrotizing pauci-immune crescentic glomerulonephritis. Despite undergoing steroid pulse therapy, the patient developed diffuse alveolar damage which finally responded to rituximab infusion.

\section{Introduction}

Granulomatosis with polyangiitis (GPA) is a systemic antineutrophil cytoplasmic autoantibody- (ANCA-) associated vasculitis that is characteristically associated with renal and respiratory disease $[1,2]$. Although patients with GPA may develop a wide variety of neurological manifestations, most of them involve the peripheral nervous system and are present in approximately $15 \%$ of patients $[3,4]$. Central nervous system involvement occurs in less than $10 \%$ of patients, with the meningeal disease being the most commonly associated with granulomatous inflammation [5]. Cerebral lesions are very rare and mostly aggressive $[6,7]$.

\section{Case Presentation}

A 56-year-old male with a past medical history significant for seropositive rheumatoid arthritis (RA) for the past 12 years was seen due to a one-week history of polyarthritis and forgetfulness in the last day. In the emergency department (ED), the physical examination was significant for moderate back tenderness with decreased range of motion, swelling, and tenderness of the metacarpophalangeal joints, wrists, ankles, and left knee. The patient's wife reported he was having trouble recalling recent events. The patient was oriented only to person and place; otherwise, he was alert, following commands, he had a steady gait, and had no focal deficit or cranial nerve involvement. The cardiac examination was normal. Given his recent lumbar laminectomy 2 months prior, a lumbar MRI was ordered in the ED which did not show any acute changes. Furthermore, a CT scan of the head without contrast was negative for stroke, intracranial hemorrhage, or other lesions. Laboratory workup showed a leukocyte count of $12.09 \mathrm{mg} / \mathrm{dL}$ and hemoglobin of $11.9 \mathrm{mg} / \mathrm{dL}$. Otherwise, no electrolyte abnormalities were noted, and serum creatinine was $0.89 \mathrm{mg} / \mathrm{dL}$ with an estimated GFR $>60$. No acute phase reactants were tested. The patient was admitted due to a suspected rheumatoid arthritis flare, his prednisone was increased to $15 \mathrm{mg}$ daily, and opioids were given for pain control. Previously, his RA was controlled with chronic use of prednisone $5 \mathrm{mg}$ daily, methotrexate $25 \mathrm{mg} \mathrm{SQ}$, hydroxychloroquine $400 \mathrm{mg}$ daily, and tocilizumab SQ $162 \mathrm{mg}$ for the last 4 years.

On the third day of hospitalization, the patient's polyarthritis showed no improvement, and thus rheumatology was consulted. A nonblanching palpable petechial rash was noted over the patient's lower extremities, and his memory 
declined as he was struggling to recall same-day events. The patient became oriented only to person, cranial nerves were intact, and no focal deficits were noted, and he was able to follow commands and had no coordination problems. Additional laboratory workup revealed proteinuria and microscopic hematuria with normal creatinine and GFR. An MRI of the brain with and without contrast showed a small region of acute infarction in the left mammillary body (Figure 1).

The patient was started on methylprednisolone IV due to concerns of systemic vasculitis with central nervous system (CNS) and kidney involvement. A CT angiography (CTA) of the head and neck showed bilateral minimal scattered plaques involving the carotid arteries without evidence of high-grade stenosis. A more thorough workup showed normal complement levels, elevated C-reactive protein $15.3 \mathrm{mg} / \mathrm{dL}$, sedimentation rate $>130 \mathrm{~mm} / \mathrm{hr}$, positive $1: 512$ C-ANCA, positive proteinase 3 antibody $>8.0$, negative $\mathrm{P}$-ANCA, positive rheumatoid factor $252 \mathrm{IU} / \mathrm{mL}$, negative cyclic citrullinated peptide antibody, negative cryoglobulin, negative dsDNA antibody, and negative ANA. Serology for acute HIV, hepatitis A, B, and C were negative, as well as histoplasma antibodies (Table 1). Echocardiogram showed normal biventricular function with an estimated EF of $55-60 \%$ and no signs of pericardial effusion or endocarditis. A kidney biopsy was also planned.

The patient was diagnosed with a C-ANCA-associated vasculitis with CNS involvement, and a treatment plan was established for methylprednisolone $500 \mathrm{mg}$ IV twice a day for 5 days followed by cyclophosphamide infusion once the patient was cleared by infectious disease. The patient's confusion, polyarthritis, and a petechial rash slowly improved after the initial corticosteroid pulse. His kidney biopsy reported focal necrotizing pauci-immune crescentic glomerulonephritis confirming the diagnosis of granulomatosis with polyangiitis (Figure 2). No creatinine elevation or abnormal GFR were seen throughout the patient's hospitalization despite the evident proteinuria and hematuria. After 5 days of methylprednisolone, the patient was discharged on prednisone $60 \mathrm{mg}$ PO daily with plans to start cyclophosphamide within the next few days. Two days later, during his outpatient follow-up with rheumatology, the patient was complaining of hemoptysis and was noted to be in moderate respiratory distress which prompted rapid readmission. A CT scan of the chest showed extensive patchy airspace disease throughout the lungs concerning for diffuse alveolar hemorrhage (Figure 3) which was confirmed with a bedside bronchoscopy. The patient was restarted on methylprednisolone $500 \mathrm{mg}$ IV twice followed by rituximab $1 \mathrm{~g}$ IV after which he achieved complete remission. The patient continues to be followed as an outpatient and is currently well controlled on rituximab infusion every 4 months.

\section{Discussion}

Cerebrovascular disease in antineutrophil cytoplasmic autoantibody- (ANCA-) associated vasculitis is exceedingly rare and tends to have a poor prognosis [6-9]. Most case reports describe a rapidly progressive clinical course with high mortality due to a subsequent hemorrhage or hemorrhagic conversion $[8,10,11]$. Additionally, in these few patients, ischemic strokes are usually present in the acute phase of the untreated vasculitis and may even be part of the initial presentation. Furthermore, different affected areas of stroke have been described including the bilateral corona radiata, the left pons, the lateral medullary, and the right medulla oblongata $[7,8,10,11]$.

This case presented with polyarthritis and forgetfulness described by his wife as an impairment to recall recent events. The patient had a history of seropositive RA with a positive RF and a negative anti-CCP. He did not improve with prednisone $15 \mathrm{mg}$ daily for the suspected RA flare, and he later presented with a purpuric rash and further decline in his mentation, which prompted the brain MRI that finally showed the small region of acute infarction in the left mammillary body. Interestingly, mammillary bodies play a prominent role in human memory formation and retrieval $[12,13]$. Although isolated infarcts to the mammillary bodies are rare, they can result in acute amnesic syndromes including transient global amnesia which is described as a temporary inability to recall recent events [12-14].

The most common etiology of ischemic strokes in patients with granulomatosis with polyangiitis (GPA) is the inflammation of medium-sized intracranial arteries with associated thrombosis, but other mechanisms have been described including cardioembolic events, arterial dissection, and direct invasion from the nasal cavity, which could explain the wide variety of CNS territories affected [11]. Moreover, a study in 2017 has described accelerated atherosclerosis in patients with ANCA-associated vasculitis reporting the presence of carotid atherosclerotic plaques in $30.4 \%$ of patients [15].

Ischemic strokes have been reported in GPA patients with no other obvious cardiovascular risk factors [8]. Our patient's cardiovascular risk factors included his history of rheumatoid arthritis and the chronic use of prednisone. On the other hand, he was on methotrexate, which has shown to reduce the overall cardiovascular disease risk in patients with RA, likely by decreasing systemic inflammation, and tocilizumab which could potentially have similar protective effects $[16,17]$. Furthermore, we performed a CTA of head and neck which showed bilateral minimal scattered plaques involving the carotid arteries without evidence of high-grade stenosis. Thus, in this particular case, acute vasculitis with associated thrombosis may have played a major role in the development of the stroke rather than any significant atherosclerosis. Also, the lack of significant carotid plaques and a normal echocardiogram makes a cardioembolic event less likely.

Aside from the challenging presentation, induction of complete remission is the goal and expectation of treatment with immunosuppressive therapy in patients with GPA $[1,18]$. Our patient clinically responded to the initial 5 days pulse of methylprednisolone, which was tapered to prednisone $60 \mathrm{mg}$ PO daily followed by cyclophosphamide infusion. However, 2 days later, he presented with diffuse alveolar hemorrhage after which rituximab was started 


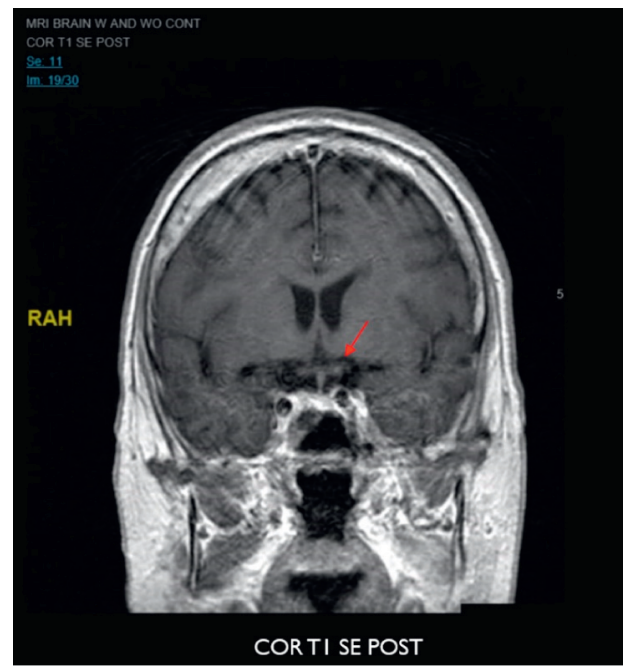

(a)

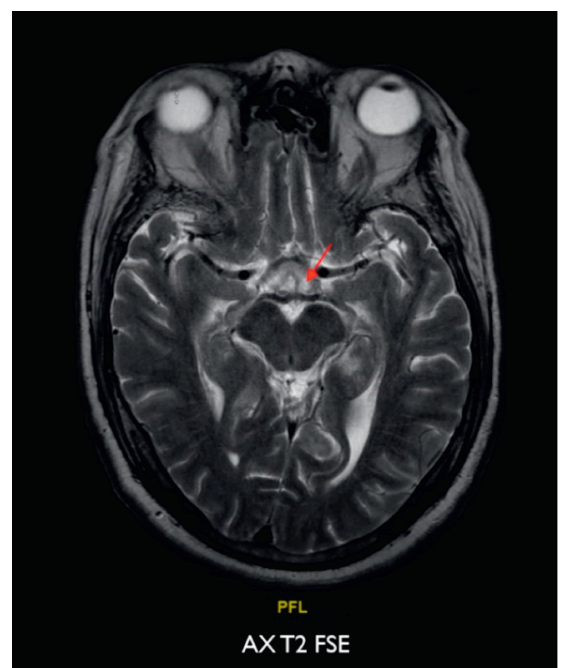

(b)

FIGURE 1: MRI of the brain with and without contrast—small region of focal water restriction at the left mammillary body consistent with a subtle infarct in this area.

TABLE 1: Laboratory data.

\begin{tabular}{|c|c|c|}
\hline Component & Result & Units \\
\hline $\begin{array}{l}\text { Complete blood cell count } \\
\text { WBC count } \\
\text { Red blood cell count } \\
\text { Hemoglobin } \\
\text { Hematocrit } \\
\text { Platelet count }\end{array}$ & $\begin{array}{c}12.09 \\
5.16 \\
11.9 \\
42 \\
370\end{array}$ & $\begin{array}{c}\mathrm{mg} / \mathrm{dL} \\
\times 106 / \mathrm{uL} \\
\mathrm{mg} / \mathrm{dL} \\
\% \\
\times 103 / \mathrm{uL}\end{array}$ \\
\hline $\begin{array}{l}\text { Comprehensive metabolic panel } \\
\text { Sodium level } \\
\text { Potassium level } \\
\text { Chloride level } \\
\text { Carbon dioxide level } \\
\text { Anion gap } \\
\text { Glucose level } \\
\text { BUN } \\
\text { Creatinine } \\
\text { Estimated CrCl AdjBW } \\
\text { Estimated GFR } \\
\text { Calcium total } \\
\text { Bilirubin total } \\
\text { AST/SGOT } \\
\text { ALT/SGPT }\end{array}$ & $\begin{array}{c}135 \\
4.7 \\
99 \\
26 \\
13 \\
108 \\
9 \\
0.89 \\
123.12 \\
>60.0 \\
8.1 \\
0.6 \\
33 \\
41\end{array}$ & $\begin{array}{l}\mathrm{mMol} / \mathrm{L} \\
\mathrm{mMol} / \mathrm{L} \\
\mathrm{mMol} / \mathrm{L} \\
\mathrm{mMol} / \mathrm{L} \\
\mathrm{mMol} / \mathrm{L} \\
\mathrm{mg} / \mathrm{dL} \\
\mathrm{mg} / \mathrm{dL} \\
\mathrm{mg} / \mathrm{dL} \\
\mathrm{mL} / \mathrm{min} \\
\mathrm{mL} / \mathrm{min} / 1.73 \mathrm{~m}^{2} \\
\mathrm{mg} / \mathrm{dL} \\
\mathrm{mg} / \mathrm{dL} \\
\mathrm{IU} / \mathrm{L} \\
\mathrm{IU} / \mathrm{L}\end{array}$ \\
\hline $\begin{array}{l}\text { Chemistry-misc } \\
\text { Antinuclear antibody (EIA) } \\
\text { dsDNA antibody } \\
\text { C-ANCA } \\
\text { P-ANCA } \\
\text { Myeloperoxidase (MPO) antibody } \\
\text { Proteinase } 3 \text { antibody } \\
\text { Complement antigen C3 } \\
\text { Complement antigen C4 } \\
\text { Cryoglobulin } \\
\text { Cyclic citrullinated peptide antibody } \\
\text { Rheumatoid arthritis Qual } \\
\text { Creatinine random urine } \\
\text { Protein random urine }\end{array}$ & $\begin{array}{c}\text { Negative } \\
\text { Negative } 2.0 \\
\text { Positive } 1: 512 \\
\text { Negative } \\
\text { Negative }<0.2 \\
\text { Positive }>8.0 \\
160.8 \\
28.6 \\
\text { Negative } \\
\text { Negative } 1.1 \\
\text { Positive } 252 \\
199 \\
70\end{array}$ & $\begin{array}{c}- \\
\mathrm{IU} \\
- \\
- \\
- \\
- \\
\mathrm{mg} / \mathrm{dL} \\
\mathrm{mg} / \mathrm{dL} \\
- \\
\mathrm{unit} / \mathrm{mL} \\
\mathrm{IU} / \mathrm{mL} \\
\mathrm{mg} / \mathrm{dL} \\
\mathrm{mg} / \mathrm{dL}\end{array}$ \\
\hline
\end{tabular}


TABle 1: Continued.

\begin{tabular}{lcc}
\hline Component & Result & Units \\
\hline Histoplasma antibodies & Negative & $\mathrm{pg} / \mathrm{mL}$ \\
1,3-beta-D-Glucan & Negative 37 & Nonreactive \\
Hepatitis A (HAAb) antibody IgM & Nonreactive \\
Hepatitis A antibody & Nonreactive \\
Hepatitis B core antibody IgM & Nonreactive \\
Hepatitis B surface antigen & Nonreactive \\
Hepatitis C antibody & Nonreactive \\
HIV1 p24 and HIV1/HIV2 antibody & \\
\hline
\end{tabular}

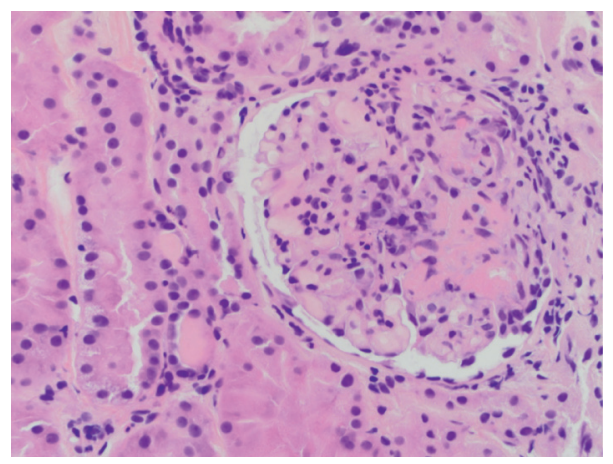

FIGURE 2: Focal necrotizing crescentic glomerulonephritis on kidney biopsy.

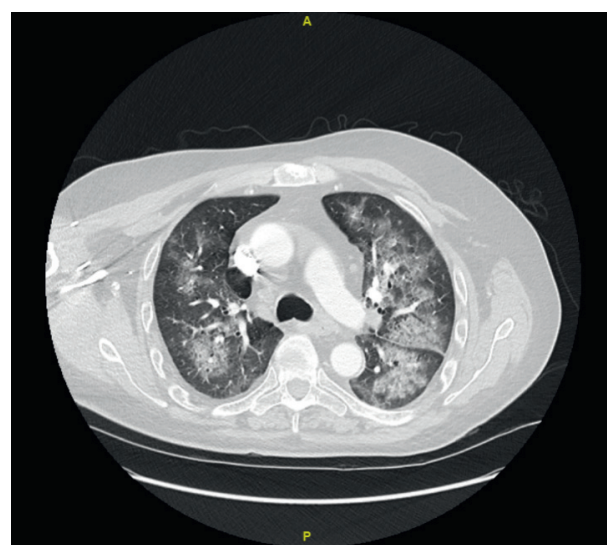

(a)

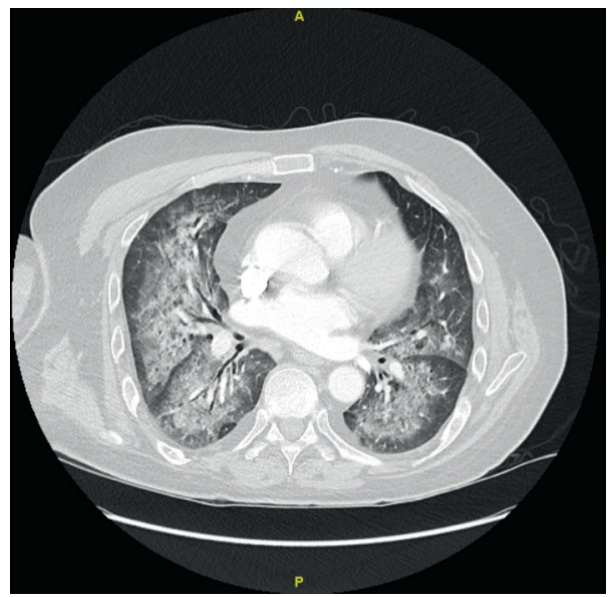

(c)

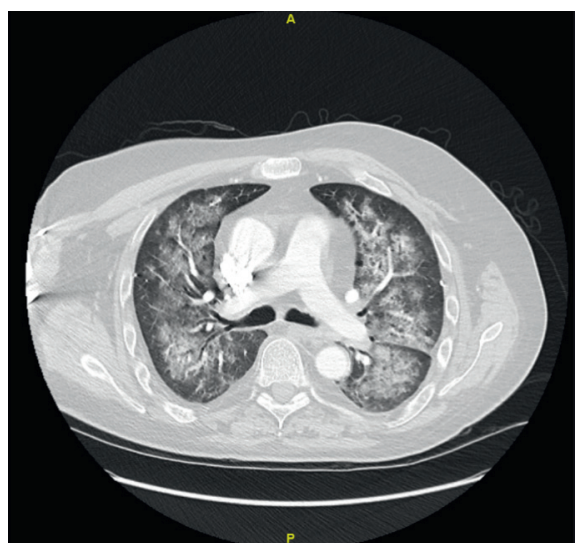

(b)

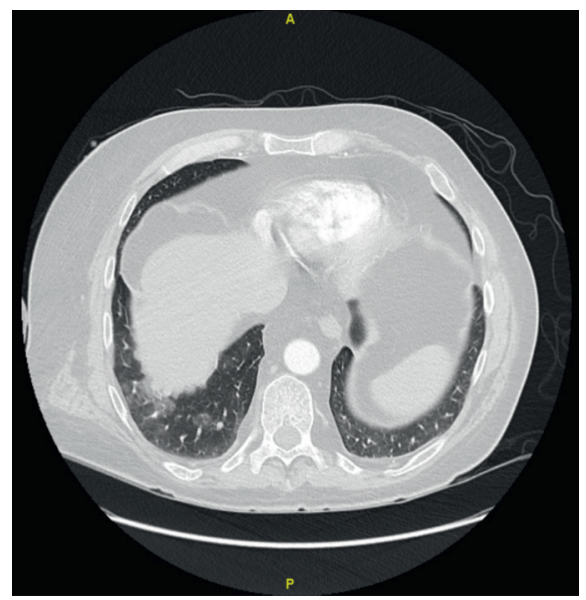

(d)

Figure 3: Extensive patchy airspace disease on CT scan of the chest with contrast. 
immediately, as it was more accessible at the moment of readmission. This clinical course could highlight the aggressive, relapsing, and unpredictable nature of ANCA-associated vasculitis with cerebrovascular disease.

Finally, the development of granulomatosis with polyangiitis in patients with rheumatoid arthritis (RA) is unexpected but has been previously documented $[19,20]$. Our patient had an established diagnosis of seropositive RA for 12 years treated with biologics, after which he developed clinical findings suggestive of systemic vasculitis with serological and histological evidence consistent with GPA.

\section{Data Availability}

All data were obtained from the patient's electronic medical records. Data have been properly displayed to protect patient's identity.

\section{Conflicts of Interest}

The authors declare no conflicts of interest.

\section{Acknowledgments}

The authors thank Peter Larsen, Ph.D., who critically revised the manuscript and approved the final draft. This work was supported by the Internal Medicine Residency Program from MercyOne North Iowa who has provided funding for the article processing charge. MercyOne North Iowa was not involved in the manuscript writing, editing, approval, or decision to publish.

\section{References}

[1] C. Comarmond and P. Cacoub, "Granulomatosis with polyangiitis (Wegener): clinical aspects and treatment," Autoimmunity Reviews, vol. 13, no. 11, pp. 1121-1125, 2014.

[2] B. Grygiel-Górniak, N. Limphaibool, K. Perkowska, and M. Puszczewicz, "Clinical manifestations of granulomatosis with polyangiitis: key considerations and major features," Postgraduate Medicine, vol. 130, no. 7, pp. 581-596, 2018.

[3] C. Pagnoux and L. c. Guillevin, "Peripheral neuropathy in systemic vasculitides," Current Opinion in Rheumatology, vol. 17, no. 1, p. 41, 2005.

[4] R. Suppiah, R. D. M. Hadden, R. Batra et al., "Peripheral neuropathy in ANCA-associated vasculitis: outcomes from the European Vasculitis Study Group trials," Rheumatology, vol. 50, no. 12, p. 2214, 2011.

[5] S. G. Arden, "Central nervous system vasculitis," Current Rheumatology Reports, vol. 5, no. 2, pp. 116-127, 2003.

[6] I. M. Bajema, E. C. Hagen, A. W. Weverling-Rijnsburger et al., "Cerebral involvement in two patients with Wegener's granulomatosis," Clinical Nephrology, vol. 47, no. 6, pp. 401-406, 1997.

[7] M. Bares, M. Muchová, M. Dufek, J. Litzman, P. Krupa, and I. Rektor, "Wegener's granulomatosis: ischemic stroke as the first clinical manifestation (case study)," Journal of Neurology, vol. 249, no. 11, pp. 1593-1594, 2002.

[8] Y. Ito, K. Suzuki, T. Yamazaki, T. Yoshizawa, N. Ohkoshi, and A. Matsumura, "ANCA-associated vasculitis (AAV) causing bilateral cerebral infarction and subsequent intracerebral hemorrhage without renal and respiratory dysfunction,"
Journal of the Neurological Sciences, vol. 240, no. 1-2, pp. 99-101, 2006.

[9] F. Mattioli, R. Capra, M. Rovaris et al., "Frequency and patterns of subclinical cognitive impairment in patients with ANCA-associated small vessel vasculitides," Journal of the Neurological Sciences, vol. 195, no. 2, pp. 161-166, 2002.

[10] N.-C. Chiari, P.-H. Lai, H.-C. Fang, K.-J. Chou, and C.-L. Chen, "Microscopic polyangiitis with an initial presentation of pontine infarction," The American Journal of the Medical Sciences, vol. 344, no. 2, pp. 163-165, 2012.

[11] O. D. Taraschenko, C. F. Amory, J. Waldman, E. K. Hanspal, and G. L. Bernardini, "Lateral medullary stroke in patient with granulomatous polyangiitis," Journal of Stroke and Cerebrovascular Diseases, vol. 23, no. 5, pp. 1259-1261, 2014.

[12] H. Hildebrandt, S. Mller, B. Bussmann-Mork, S. Goebel, and N. Eilers, "Are some memory deficits unique to lesions of the mammillary bodies?" Journal of Clinical and Experimental Neuropsychology, vol. 23, no. 4, pp. 490-501, 2001.

[13] S. Male and R. Zand, "Isolated mammillary body infarct causing global amnesia: a case report," Journal of Stroke and Cerebrovascular Diseases, vol. 26, no. 3, pp. e50-e52, 2017.

[14] K. Amuluru, C. G. Filippi, and A. Lignelli, "Acute amnesia due to isolated mammillary body infarct," Journal of Stroke and Cerebrovascular Diseases, vol. 24, no. 10, pp. e303-e305, 2015.

[15] I. González-Suárez, J. J. Ríos-Blanco, and J. Arpa, “Accelerated atherosclerosis in ANCA-associated vasculitis," Acta Neurologica Scandinavica, vol. 136, no. 6, pp. 688-693, 2017.

[16] J. L. Marks and C. J. Edwards, "Protective effect of methotrexate in patients with rheumatoid arthritis and cardiovascular comorbidity," Therapeutic Advances in Musculoskeletal Disease, vol. 4, no. 3, pp. 149-157, 2012.

[17] S. Singh, M. Fumery, A. G. Singh et al., "Comparative risk of cardiovascular events with biologic and synthetic diseasemodifying antirheumatic drugs in patients with rheumatoid arthritis: a systematic review and meta-analysis," Arthritis Care \& Research, vol. 72, no. 4, pp. 561-576, 2020.

[18] J. P. Singh 3rd, A. Derhovanessian, H. Tazelaar, and J. A. Belperio, "Granulomatosis with polyangiitis (Wegener's Granulomatosis): evolving Concepts in Treatment," Seminars in Respiratory and Critical Care Medicine, vol. 39, no. 4, pp. 434-458, 2018.

[19] D. Spoerl, Y. M. Pers, and C. Jorgensen, "Anti-neutrophil cytoplasmic antibodies in rheumatoid arthritis: two case reports and review of literature," Allergy, Asthma \& Clinical Immunology, vol. 8, no. 1, p. 19, 2012.

[20] A. Capdevila-Reniu, S. D. 1. C. Rodríguez-Garcia, I. Grafia et al., "Localised granulomatosis with polyangiitis in an older patient with rheumatoid arthritis," Age and Ageing, vol. 49, no. 1, pp. 146-148, 2019. 